\title{
Diploma students' perspective: Pursue or not to pursue a degree in accountancy?
}

\author{
Nor'aini Awab ${ }^{1, *}$, and A.H. Fatima ${ }^{2}$ \\ ${ }^{1}$ MARA Professional College \\ ${ }^{2}$ International Islamic University Malaysia
}

\begin{abstract}
This is an exploratory study which investigates the reasons influencing Diploma in Accountancy (DIA) students' intention to pursue or not pursue a Bachelor of Accountancy (BAcc) degree programme. The Theory of Reasoned Action (TRA) is used as a basis for the study. The research involves collecting primary data through survey questionnaires. 250 questionnaires were distributed to the final year DIA students in MARA Professional College. Based on the findings, the reasons that influence students' intention to pursue are: the hope to earn a good salary, higher future earnings potential and greater employability in the future. In contrast, the reasons for non-pursuance of a BAcc programme are because students think that they can develop their potential for personal growth and career development with other degree programmes or they want to get jobs and start working after obtaining the DIA. These findings would be useful to the Ministry of Education, the universities as well as the professional bodies to ensure that the students continue their studies in the accounting discipline to achieve their full potential.
\end{abstract}

\section{Introduction}

In Malaysia, a diploma programme is one of the many entry routes to a degree programme. This route is an additional opportunity for, mainly Bumiputera, students who could not enter into a degree programme due to academic or financial reasons. Similarly, students who complete their Diploma in Accountancy (DIA) programmes can opt to pursue the Bachelor of Accountancy (BAcc) programme. MARA Professional College or Kolej Professional MARA (KPM) is one of the Malaysian institutions that offer the DIA programme. KPM is managed by the Majlis Amanah Rakyat or Public Trust Council (MARA). One of the main objectives of KPM is to provide technical and skill based competence to Bumiputera students, who fail to meet entry requirements into the matriculation programme at any university [1]. These students, who are normally from rural

* Corresponding author: norainiawab08@gmail.com 
and financially disadvantaged backgrounds are given an alternative route to better employment opportunities or higher education through KPM.

Unfortunately, the report from KPM to the Ministry of Education (MOE) on 2005 2012 statistics revealed that only about $19 \%$ of the DIA graduates pursued their studies to a bachelor degree. Out of this percentage, some of the DIA graduates chose to continue their studies in other fields, such as Bachelor in Management, Business Studies, Marketing and Finance. Thus, a very small percentage pursued the BAcc programme.

Since a degree in BAcc is normally a stepping stone towards attaining a professional accounting qualification, particularly for Bumiputera students, the concern is that these students will fail to proceed towards a career as a professional accountant. This problem is considered dire, as only 8 percent of professional accountants registered by the Malaysian Institute of Accountants (MIA) are Bumiputera. Therefore, the Malaysian government and the MIA are encouraging more Bumiputera accountants. However, their plans may be hampered if a significant percentage of these Bumiputera students from the DIA programme do not follow through by pursuing a BAcc degree nor a professional qualification later.

Therefore, it is vital for this study to investigate and explore the possible reasons that could lead these students to either pursue or hinder them from pursuing the BAcc programme. This study is essential as it provides needed baseline information to institutions that offer the DIA programme, particularly KPM. The lecturers from the DIA programmes could highlight the facts that are in line with reasons for DIA students to pursue the BAcc programme. At the same time, DIA programme lecturers could pacify concerns that the students may have to enable them to pursue a BAcc programme.

Moreover, this study is timely because accounting departments in higher learning institutions can use these findings in their strategies to increase students' enrolment. Based on the reasons provided by the students, the MOE and universities could then promote the factors that would enable these students to pursue a BAcc degree and alleviate the factors that would deter them from doing so. Furthermore, DIA students from KPM tend to come from less financially advantaged family backgrounds, thus this may also affect their pursuance of a BAcc programme. Hence, this study extends the literature, which mainly focuses on factors that influence the decisions of secondary school students to further their studies in accounting at the tertiary level, whereas others focus on factors that influence accounting graduates from pursuing a professional qualification.

The next section reviews the relevant literature, followed by a discussion on the theory and research method. Subsequently, the findings are discussed prior to concluding the study.

\section{Literature review}

Several factors influence decision making [2], thus understanding these factors is important to comprehend the outcome. Prior studies have investigated intrinsic and extrinsic factors in various contexts [3], however the review of the literature will focus on Malaysian students' decisions to major in accounting.

Factors influencing students' intention to enrol in BAcc degree were investigated on 173 students from public and private higher learning institutions in Penang and Kedah [4]. The results logically showed that students intend to enrol in the BAcc when they have a positive attitude towards it. On the other hand, a survey was conducted on the first batch of 50 accounting students in Universiti Malaysia Sarawak, to identify the factors influencing the decision of these students to accept the offer of accounting as a major [5]. The study revealed that job prospect has a significant influence over the students' decision to choose accounting. Similarly, a survey was carried out on 400 students from the International 
Islamic University Malaysia and Tunku Abdul Rahman College [6]. The study was conducted on the influential factors of students' intention to enrol in the accounting programme. The factors were divided into three categories: attitude towards accounting (ATT), subjective norm (SN) and amount of information on accounting (AIA). Their findings showed that ATT, SN and AIA significantly influenced the male students' intention to enrol in the accounting programme; while the female students were mostly influenced by ATT and SN.

In examining the Bumiputera DIA students in Malaysia, 65 questionnaires were distributed to selected respondents in final year DIA programme [7]. It was found that the decline in the number of students enrolling in the BAcc programme was due to the decline in the number of students achieving the required CGPA to be eligible to enrol in the programme. The findings also reveal that the university, lecturers and students all have significant roles to play in helping the students to obtain the desired result. Another study conducted a survey on 66 final year DIA students in UiTM Kedah [8]. However, this study focused on the factors influencing the students' decision to pursue professional accounting qualification. The two main influencing variables were CGPA and the availability of a study grant.

The review of the literature indicates that in the Malaysian context, the studies tend to investigate accounting students' decision to select accounting as a major subsequent to their joining the BAcc programme. Thus, the sample may be positively biased. However, DIA students come from a different route, hence may have other motivations to pursue or not to pursue a BAcc programme. The literature review has shown that there are limited studies on DIA students, particularly in relation to their pursuing a BAcc programme.

\section{Theory and research method}

This study refers to the Theory of Reasoned Action (TRA), which was theorised by Martien Fishbein and Icek Ajzen [9, 10]. TRA suggests that a person's behaviour is determined by his or her intention to perform the behaviour and that this intention is, in turn, a function of his or her attitude towards the behaviour and subjective norms. In this study, a DIA student's intention to pursue a BAcc programme is predicted by his or her attitude towards the programme, and the student's perception towards it may be influenced by several factors. However, since DIA students are a largely unstudied population, in this context this study is deemed exploratory in nature. Since the aim of the study is to explore and discover the factors that influence DIA students' decision, the TRA is only referred to as a basis of study, thus the research has not specifically categorised the influencing factors into attitude nor subjective norms. Furthermore, being exploratory, the study was unable to draw a hypothesis.

The questionnaire survey method is used to collect this study's data. The questionnaire was adapted from prior literature [8, 11, 12, 13]. Subsequent to the demographic information in Section A of the questionnaire, the study enquires on the respondent's intention to pursue a BAcc programme in Section B. If the respondent's answer is a 'Yes' in this section, the respondent will proceed to answer Section C. In contrast, if it is a 'No', the respondent will answer Section D. There are 18 items each in Sections C and D to measure the reasons to pursue or not to pursue a BAcc programme, respectively. Both these sections use a five-point Likert scale ranging from $1=$ 'No Influence' to $5=$ 'Very Strong Influence' and $1=$ 'Strongly disagree' to $5=$ 'Strongly agree', respectively.

After conducting the pilot test, the questionnaires were distributed to a total of 250 final year DIA students in four KPMs: KPM Indera Mahkota, Kuantan, KPM Beranang, Selangor, KPM Ayer Molek, Melaka and KPM Bandar Penawar, Kota Tinggi, Johor. Final year students were the target respondents as they were contemplating their future following 
graduation. The response rate was $82 \%$. Then, the data was analysed primarily using 'means' to determine the extent of influence of each factor.

\section{Results and discussion of findings}

Reflecting the general demographics of the population of DIA students, $73 \%$ of the respondents were female students. Out of the 205 students who responded to the questionnaire, 153 students $(75 \%)$ intend to pursue a BAcc programme. The remainder $(25 \%)$ do not intend to pursue a BAcc programme. From the 52 students who do not want to pursue a BAcc programme, $19.2 \%$ and $55.8 \%$ intends to pursue a professional qualification or other degree programmes, respectively. Means have been used to measure the reasons to pursue and not to pursue a BAcc degree. The standard deviations for these reasons are minimal and ranges between 0.363 and 0.639. Having acceptable standard deviation is logical as this data is primary data gathered through questionnaires. Furthermore, the Likert scale ranges from between 1 and 5, hence there are no extreme values.

The means in Table 1 have been ranked from the highest to lowest to indicate the most to least influential reasons. Analysing Table 1, the main factor to motivate students to pursue a BAcc programme is a good salary as shown by the first 3 items. The potential for personal and career development is the next reason, followed by genuine interest in figures. It is interesting that the students consider their interests and self development first before employability opportunities, which is ranked next. Then, the students consider contribution to the society and prestige as a BAcc degree holder. The importance of income potential and job prospects is consistent with prior literature [7, 14].

Table 1. Reasons to pursue BAcc programme

\begin{tabular}{|l|c|}
\hline \multicolumn{1}{|c|}{ Statement } & Mean \\
\hline I hope to get a good salary after obtaining a BAcc degree & 4.177 \\
\hline The salary offered to BAcc graduates is higher compared to other graduates & 4.078 \\
\hline There is future high earnings potential with a BAcc degree & 3.961 \\
\hline There is potential for personal growth and career development with a BAcc & 3.935 \\
\hline I genuinely am interested in numbers and calculations & 3.895 \\
\hline There are greater employability choices with a BAcc degree & 3.83 \\
\hline I will be able to positively contribute to the society if I have a BAcc degree & 3.771 \\
\hline It is prestigious to have a BAcc degree (status highly valued by the public) & 3.732 \\
\hline $\begin{array}{l}\text { I am quite confident that I will be able to attain financial assistance or study grant to } \\
\text { pursue my studies }\end{array}$ & 3.719 \\
\hline I have to satisfy my family's hopes and dreams & 3.68 \\
\hline Obtaining a BAcc ensures good physical working environment and condition & 3.66 \\
\hline Obtaining a BAcc enhances decision making ability & 3.654 \\
\hline I am interested in course or subjects taught in the programme & 3.536 \\
\hline There is job security for a BAcc holder & 3.569 \\
\hline I am influenced by my teachers / lecturers / instructors / counsellors & 3.484 \\
\hline Obtaining a BAcc enables the attainments of power and authority in an organization & 3.458 \\
\hline I am influenced by my friends & 3.007 \\
\hline I may not be able to get a job after the Diploma & 2.928 \\
\hline
\end{tabular}


Other factors that are taken into consideration in deciding to pursue a BAcc programme is the availability of scholarships. According to the results, family plays a more influential role than lecturers and friends. The students are also relatively confident about getting a job upon graduating from DIA.

In contrast, Table 2 lists the reasons not to pursue a BAcc programme. The top five items that influences students not to pursue is basically related to two factors: (1) They can still attain desired goals (i.e. personal and career development, enhance decision making ability and contribute to society) with other degree programmes. (2) They need to get a job, which they are quite certain they will get, after their DIA to help their families financially. The two items (items 2 and 3), which make up the second factor have identical means. The second factor is logical as these DIA students generally come from rural areas and relatively financially disadvantaged families.

Table 2. Reasons not to pursue BAcc progamme

\begin{tabular}{|l|c|}
\hline \multicolumn{1}{|c|}{ Statement } & Mean \\
\hline $\begin{array}{l}\text { I can develop my potential for personal growth and career development with other } \\
\text { degree programmes }\end{array}$ & 3.365 \\
\hline I think that I will be able to get a job after the Diploma & 3.346 \\
\hline I have to start working with a Diploma to help and satisfy family's financial needs & 3.346 \\
\hline I will be able to positively contribute to the society if I have other degrees. & 3.25 \\
\hline I can still enhance my decision making ability even without a BAcc degree & 3.115 \\
\hline $\begin{array}{l}\text { Obtaining other degree programmes enables the attainments of power and authority in } \\
\text { an organization }\end{array}$ & 3.039 \\
\hline I can obtain future high earnings potential even without a BAcc degree & 3.039 \\
\hline There is greater employability with other degree programmes. & 2.942 \\
\hline The salary for a Diploma holder adequate and I am satisfied with it. & 2.846 \\
\hline I am not interested in course or subjects taught in the programme & 2.808 \\
\hline Obtaining a BAcc degree doesn't ensure good working conditions. & 2.673 \\
\hline My friends told me not to pursue BAcc programme as it is difficult to pass & 2.596 \\
\hline There is no difference in salary of BAcc graduates compared to other graduates & 2.558 \\
\hline $\begin{array}{l}\text { I don't think I will be able to get financial assistance or study grant to pursue my } \\
\text { studies }\end{array}$ & 2.558 \\
\hline There is no job security even with a BAcc degree in the current competitive job market & 2.442 \\
\hline There is nothing prestigious about a BAcc degree holder. & 2.423 \\
\hline $\begin{array}{l}\text { My teachers/lecturers/instructors/counsellors advised me NOT to pursue a BAcc } \\
\text { degree }\end{array}$ & 2.346 \\
\hline I dislike numbers and calculations & 2.154 \\
\hline
\end{tabular}

The means close to ' 3 ' indicate that the students were 'neutral' in relation to other items. As for the last four items, although these students do not intend to pursue a BAcc degree, they still consider that a BAcc degree holder has job security and prestige. This is because means close to ' 2 ' is a 'disagree' to the statements. These students also disagree that their lecturers advised them not to pursue a BAcc and that they disliked numbers.

\section{Conclusion}

In analysing the main reasons for both pursuing and not pursuing a BAcc programme, the students seem to be fixated on earning a salary. This is reasonable if they need to help their 
families' financial circumstances. Having to earn a salary is also a deterrent to pursuing a BAcc programme as these students need to start working immediately after graduating from DIA and help their families financially. Therefore, in addition to the financial assistance and scholarships given by the government and various institutions, the universities that offer the BAcc programme may need to become more innovative and offer part-time BAcc programmes that cater to full-time working students.

The limitation of this study is that it only focused on DIA students from KPM, thus future studies could expand the sample to other diploma programmes and higher learning institutions. Furthermore, the findings of this study have to be confirmed through focus group discussion or interviews with the students. Nevertheless, the findings are useful to the MOE, KPM and universities to ensure that more Bumiputera students pursue a BAcc degree in their career path to becoming a professional accountant.

\section{References}

1. Majlis Amanah Rakyat. Higher Education Division. http://www.mara.gov.my/en/bah.pendidikan-tinggi (2015)

2. C. Dietrich. Student Pulse 2, 1 (2010).

3. A. Djatej, Y. Chen, S. Eriksen, D. Zhou. Global Perspectives Acc. Ed. 12, 53 (2015)

4. B. Zainin. University Science Malaysia Doctoral Thesis (2001)

5. S. Ali, M. IUP J Accounting Research \& Audit Practices 12, 25 (2013).

6. G. Zandi, M. Sulaiman, B. Naysary. irep.iium.edu.my/30401/1/The Academic gender. pdf (2013)

7. S. Mohamad, F. Bujang. J of Fin Reporting \& Accounting 5, 41 (2007)

8. N. Omar. Master Dissertation Universiti Utara Malaysia (2009)

9. M. Fishbein, I. Ajzen. Belief, attitude, intention \& behaviour: An introduction to theory \& research (1975)

10. I. Ajzen, M. Fishbein, M. Understanding attitudes \& predicting social behaviour (1980)

11. S. Felton, N. Buhr, M. Northey. Issues in Acc. Ed. 9, 13 (1994)

12. F. Abdul Halim, B.W. Yap, M.A. Lazim. Conference on Scientific \& Social Research 2005 Proceedings (2005)

13. M.R. Ramlan, R. Ishak, M.'A. Md Yusof. Universiti Utara Malaysia Project Report (2003)

14. F.A. Gul, B.H. Andrew, B.H., S.C. Leong, Z. Ismail. Acc \& Fin 29, 93 (1989) 